\title{
Improving Through Employee Participation. The Case of a Spanish Food Manufacturer
}

\author{
Iván González-Boubeta (iD, Iago Portela-Caramés (iD, J. Carlos Prado-Prado iD \\ University of Vigo (Spain) \\ ivangonzalezboubeta@uvigo.es,iagportela@uvigo.es,jcprado@uvigo.es
}

Received: October 2020

Accepted: December 2020

\begin{abstract}
:
Purpose: Employee participation is considered a fundamental pillar to implement continuous improvement. Based on this consideration, this article presents an action research case study in a large food manufacturer where employee participation is implemented. The experience has a two-fold objective: improve performance of the production system and make the participative philosophy deep-rooted among workers.
\end{abstract}

Design/methodology/approach: The authors implement a structured participation system, establishing an approach of empowerment and focusing on the creation of suitable organizational structures. Under those premises, improvement teams were created on each of the firm's production lines. Once the participation of the workers is finished, they were given a questionnaire to assess how deep-rooted the participative culture had become.

Findings: The results show a remarkable improvement in the efficiency of manufacturing processes, as well as the consolidation of a participative philosophy. However, there are notable differences in the results obtained for each improvement team.

Research limitations/implications: The differences obtained in the results highlight certain issues that future research must tackle. These include the way in which the staff should be rewarded for their participation or what the influence of the organizational context is when setting improvement objectives.

Practical implications: The positive results obtained support the methodology proposed by the authors for structuring participation. Organizations can set up projects of this type to improve their competitiveness while at the same time strengthening the commitment of their personnel.

Originality/value: This is one of the first studies in the field of employee participation that jointly assess the economic area and the cultural and organizational plane.

Keywords: employee participation, employee empowerment, improvement teams, efficiency, lean management, action research

\section{To cite this article:}

González-Boubeta, I, Portela-Caramés, I., \& Prado-Prado, J.C. (2021). Improving through employee participation. The case of a Spanish food manufacturer. Journal of Industrial Engineering and Management, 14(3), 405-424. https://doi.org/10.3926/jiem.3362 


\section{Introduction}

The highly turbulent and changeable environment in which firms operate today means that organizations have had to rethink the way they manage their activity. Customer demands are tending towards obtaining products and services as quickly and as cheaply as possible, but with high levels of variety and performance (Fullerton, Kennedy \& Widener, 2014). To this already complex situation must be added the growing and voracious competitiveness that exists between firms, which in many cases are fighting for the same market share and offering similar products and services. That is why becoming the organization the consumers choose to meet their needs is no trivial feat.

A large group of authors, including notable contributions from Graham C. Stevens (Stevens, 1989) and Martin Christopher (Christopher, 2000), proclaimed in their day, almost as pioneers, the importance of logistics and supply chain management as the way to obtain a competitive advantage. Their claims managed to point the spotlight on agile and coordinated management of flows of materials and information along the production line or service provision, conferring a leading role on this discipline in the business world. That new and surprising approach, which at the time could have seemed exaggerated, is now generally accepted. However, given that the current world, and the business world in particular, is characterized by how limited resources are, a criterion of efficiency is needed (Fadaki, Rahman \& Chan, 2019). In the literature on organizational management, references to philosophies that are committed to improving efficiency in this area have proliferated, such as Lean Management, Six Sigma or Total Quality Management. However, despite each philosophy having its own approach, the principles and methodology they champion are similar in practically all cases (Fredriksson \& Isaksson, 2018).

Stimec and Grima (2019), together with other authors (Roemeling, Land \& Ahaus, 2017; Tortorella, Marodin, Miorando \& Seidel, 2015), have supported continuous improvement as one of the pillars upon which the above approaches sit. In this way, continuous improvement has been defined at in different ways on many occasions (Bessant \& Francis, 1999; Boer, Berger, Chapman \& Gertsen, 2017; Prado-Prado, 2009), which means that there is currently no full consensus on one definition. Indeed, according to Singh and Singh (2015), this fact is one of the main obstacles to its implementation because the wide variety of nuances that exist tend to generate confusion in deployment. However, despite this difficulty, Brunet and New (2003) have been able to describe its main features:

- It is an exhaustive, continued approach dealing with the processes of an organization that aims to improve performance, efficiency and quality

- Generally, it is incremental in nature, in contrast to the radical technological innovations usually initiated by management. Similarly, it does not usually involve major consumption of economic resources

- It is participative, requiring the involvement of all workers, particularly those at the most operational levels of the organization

This last point refers to the mechanism par excellence for channeling continuous improvement, which is none other than employee participation. This is due to the great consensus that exists regarding the importance of this mechanism when implementing an improvement approach (Boer et al., 2017; Prado-Prado, García-Arca \& Fernández-González, 2020; Singh \& Singh, 2015). Thus, authors such as Jørgensen, Boer and Gertsen have come to define continuous improvement as an approach in which "all members of the organization contribute to improving performance by continuously implementing small changes in their work processes" (Jørgensen, Boer \& Gertsen, 2003: page 1260).

Given the above statements, it is easy to understand that much of the success of a continuous improvement approach will depend on how employee participation is carried out (García-Arca \& Prado-Prado, 2011). In this regard, there are many ways to do so, both formally and informally. At the same time, it can be done individually, with suggestions systems being the most common formula, or in groups, with classic quality circles or improvement groups as top representatives. These and other common formulas can be used to channel the potential that exists among workers at the most operational levels, which is where most improvement opportunities lie (Marksberry, Church \& Schmidt, 2014). However, many firms have not been able to structure participation adequately, which has led them to obtain results that are relatively unsuccessful or incoherent with the organization's objectives 
(Marín-García, Pardo del Val \& Bonavía Martín, 2008). That is why it is of vital importance to structure participation adequately and even, in many cases, manage it.

The importance of employee participation in the sphere of continuous improvement contrasts greatly with the amount of attention it has received in the literature (Leach, Stride \& Wood, 2006). Authors such as Lam, O'Donnell and Robertson (2015) or García-Arca, Prado-Prado and Fernández-González (2018) have highlighted the existence of a gap between the improvement of operations in a business environment and employee participation. Indeed, that gap in the literature is even greater when referring exclusively to studies on participation experiences which describe a methodology for setting up a structured system (García-Arca \& Prado-Prado, 2011). For this reason, and in a bid to fill the gap in the literature, this article presents a case of improvement in the production system of a firm by means of employee participation. This experience, framed within the action research methodology, seeks to a two-fold objective: improve the production system's performance and make the participative philosophy more deep-rooted among workers. The latter point is relevant because of the demonstrated link between the human, cultural and organizational dimension and the sustainability of improvement programs (Jaca, Viles, Mateo \& Santos, 2012). Thus, attention does not only focus on obtaining short-term results but also on guiding the organization towards continuous improvement in a sustained way.

With those considerations in mind, the paper is organized as follows. Section 2 describes the approach used for the research and presents the organizational structures set up to deploy the project. Section 3 focuses on improvement teams, paying particular attention to the key factors in the design and operation of those teams. Section 4 develops the experience in a major Spanish food manufacturer. Sections 5 and 6 present and discusses the results, both at an economic level and at a cultural and organizational level. Finally, Section 7 points out the main conclusions drawn from the study together with a series of guidelines for future research.

\section{Research Methodology}

An improvement program addressed from a participative perspective must have the organization's personnel as a fundamental pillar. Under that premise, this section describes the methodology followed by the authors, with fundamental emphasis on two aspects: the research process and the organizational structures. The definition of these points is vital to link the involvement of the staff with the objectives of the organization and of the researchers themselves.

\subsection{Action Research Approach}

The aim and characteristics of the organizational challenge presented here led the researchers to opt for application of what is called the action research approach. This methodology, which is often referred to in the literature as "research in action" (Coughlan \& Coghlan, 2002) as opposed to the "research about action" typical in traditional case studies, possesses a strong link with the nature of this case. This relationship can be seen in the Reason and Bradbury's definition of this approach as one that "seeks to bring together action and reflection, theory and practice, in participation with others" (Reason \& Bradbury, 2001: page 2), which makes express reference to the participative philosophy. Furthermore, carrying out a disruptive program within an organization, for improvement purposes or any other, requires there to be a motivating agent or facilitator. The action research approach responds to that question because when used in studies the researcher takes on that role and takes a side within the system as an agent of change (Näslund, Kale \& Paulraj, 2010).

The firm under study is a major food manufacturer located in the north-west of Spain. Its facilities comprise three factories, each of which makes a different family of products. Likewise, within each factory are three distinct independent production lines, each making a specific product. All the lines work in a similar way, being in the three cases chain processes that combine posts with a significant level of automation with others of totally manual work. This makes the role of the people working on the lines vital when it comes to improving performance. In terms of workforce, the firm has over 300 workers on indefinite term contract who are highly multi-skilled. All the factories work non-stop for three 8-hour shifts per day.

Given these considerations and bearing in mind the framework in which the experience is developed, the research process is structured as follows (Figure 1): 
- Pre-phase: Understanding context and global vision

- Phase 1: Data gathering

- Phase 2: Data analysis and action planning

- Phase 3: Action implementation and evaluation

- Meta-phase: Monitoring

These phases, based on the precepts described by Coughlan and Coghlan (2002) and Fernández Vázquez-Noguerol, Rodríguez-García and Prado-Prado (2018), make up a cyclical structure that runs throughout the whole experience. Thus, once pertinent actions have been implemented, data gathering starts again in order to verify effectiveness and assess whether new actions should be taken. Leadership in executing these stages is the task of the researchers, considered experts in undertaking projects based on participation mechanisms.

The complete three-stage cycle is applied to the whole production system of the firm, that is, to each of its production lines. However, once a global vision of the production system has been gained, this approach should be carried out "downstream" and put into practice for each of the problems or deficiencies identified (Fagundes, Amorim \& da Silva Lima. 2017). For that reason, there may be times when implementation of improvement actions coexists with data gathering for other issues. This is considered by the authors as a vital aspect that gives the experience some dynamism, without forgetting that it is the organization's own workforce that must executing the actions. In the same way, the role of the researchers throughout the project should gradually decrease in order for the firm's management to take on the jobs of leadership and coordination. This is a fundamental question in order instill the philosophy of participation. In any case, at the beginning of the project, there is particular emphasis on making the role of the researchers clear, as is recommended by van Aken, Chandrasekaran and Halman (2016).

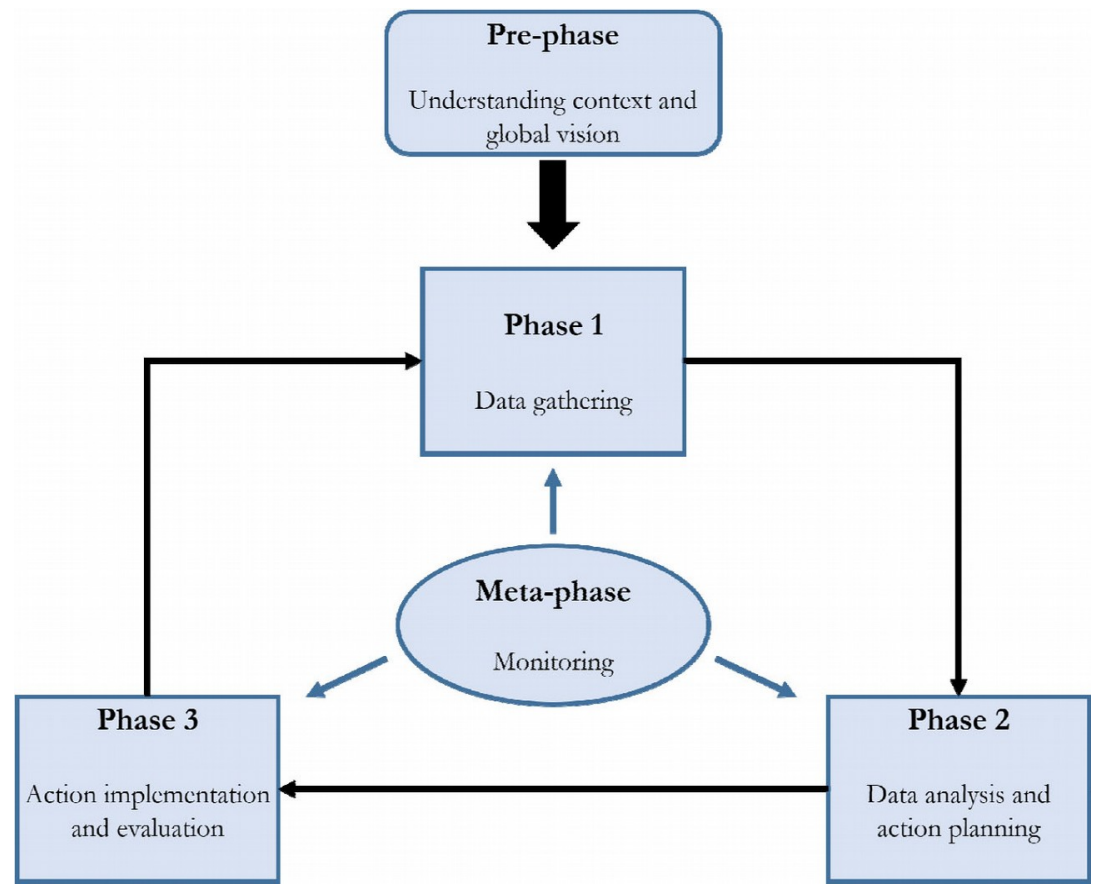

Figure 1. Action research cycle adapted from Coughlan and Coghlan (2002) and Fernández Vázquez-Noguerol et al. (2018)

\subsection{Organizational Structures}

Once the approach of the research has been defined, the design of the organizational mechanisms must be taken on. In a project based on employee participation, in which predictably a great number of people and a large amount of information are involved, it is vital to structure the tasks and functions to be performed (García-Arca \& Prado-Prado, 2011). Just choosing the participation modality is usually not enough if resources are not provided to the system or it is not structured properly. When addressing this issue, it is key to pay attention to the factors that 
are critical to the success of such systems. In this regard, several authors (Jaca, Viles et al., 2012; Marín-García \& Bonavia, 2015; Marín-García et al., 2008; Prado-Prado et al., 2020; O'Donoghue, Stanton \& Bartram, 2011) have been able to identify those factors in their research. Figure 2 summarizes these aspects, sorting them according to their role in the structuring of participation.

Looking at the motivational or cultural factors, it can be seen that one of the pillars for successful participation is support and commitment from everyone in the organization. That is why it is necessary to have a system that allows collaboration from everyone and avoids any contributions being forgotten. The latter is a particularly important aspect when one of the objectives is sustainability of the participative culture (Jaca, Viles et al., 2012). Not considering this question could give rise to employee demotivation and lead to workers seeing their participation as pointless (Rapp \& Eklund, 2002). Luckily, commitment from the firm's management with initiatives that promote personnel involvement has always been a clearly tangible aspect. Among other aspects, this commitment is reflected in the creation of a specific continuous improvement area during the months before to this experience. However, this department had previously focused some of its efforts on responding to proposals from personnel in an informal way and not necessarily aimed at improving competitiveness.
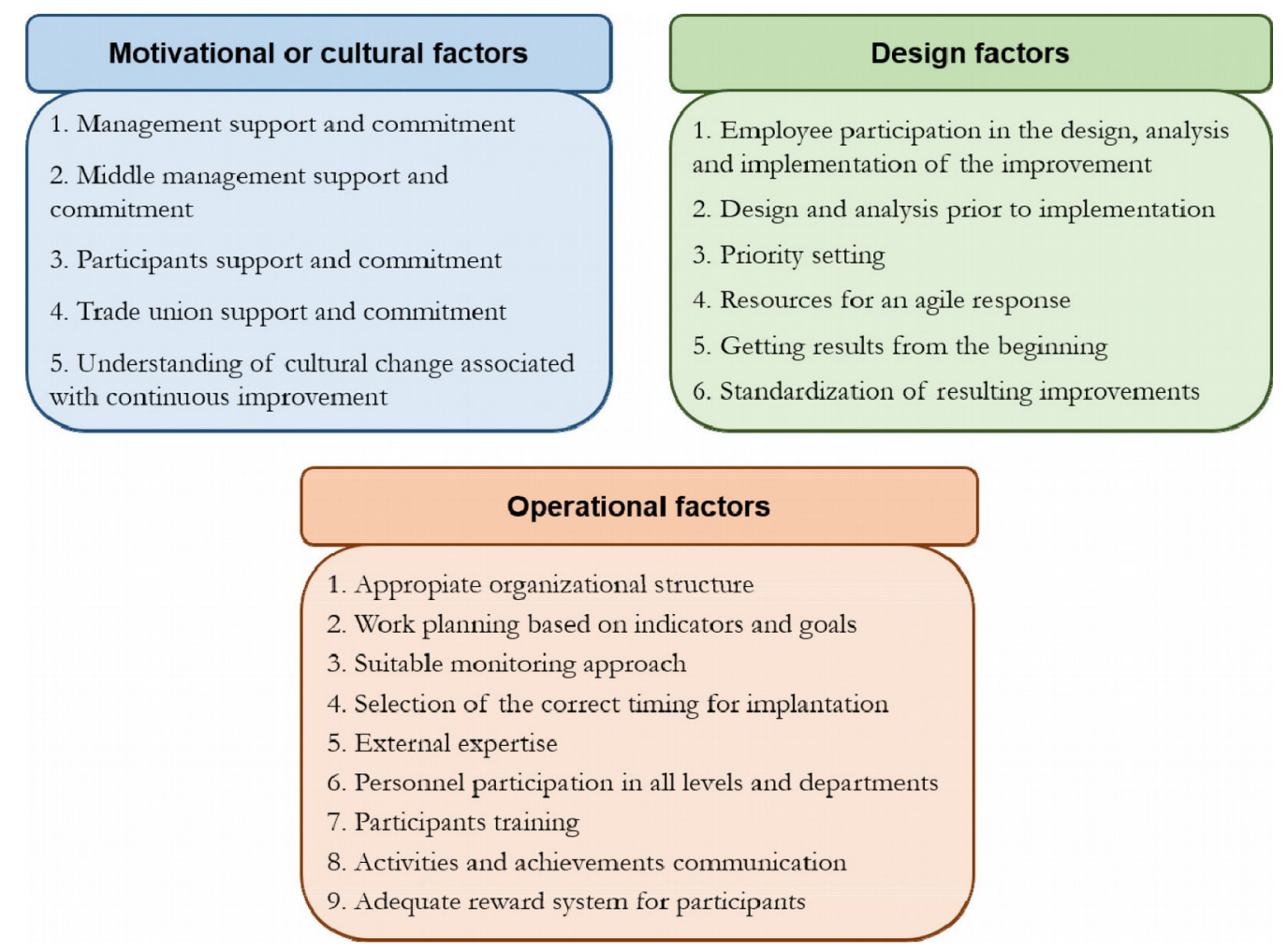

Figure 2. Critical factors for employee participation success

Bearing this framework in mind, below is a description of the organizational structures to be implemented. Each one is directly related to an organizational level depending on the activities attributed to them. They are:

\subsubsection{At Operational Level - Improvement Team}

The structure selected to introduce participation into the most operational levels of the organization is the "improvement team". This structure is made up of workers from a specific production line and led by the main supervisor for that line, who is called the "coordinator". The job of this team lies in identifying, studying and implementing improvements of their own work environment. The functioning and constitution of this organizational structure are explained in detail in section 3 of this article. 


\subsubsection{At Tactical Level - Implementation Team}

The organizational structure implemented at a tactical level is called the "implementation team". This structure is made up of the main managers in the firm's production and continuous improvement areas together with the researchers. In this regard, it is worth noting that the improvement team coordinators also form a part of the implementation team, acting as a link between both teams.

The work of the people involved in the implementation team comprises an important set of tasks. The main ones are to monitor the work of the improvement teams and to evaluate the effectiveness of their actions. Another of their functions is to guide the teams towards deficiencies or opportunities that could have greater impact on the organization's competitiveness. They also collaborate, when necessary, with the improvement teams in analyzing specific situations which turn out to be complex or when the implications require a more senior view or more technical knowledge.

\subsubsection{At Strategic Level - Monitoring Committee}

Finally, there is a group of people who are responsible for overseeing the correct functioning of the participation mechanisms at a macro level, called the "monitoring committee". This committee is made up of the firm's management and the researchers. In addition to carrying out monitoring tasks, this group also has the mission to deal with problems or improvement opportunities that, because of their implications, may require a decision at a more strategic level (investments, policy changes, etc.).

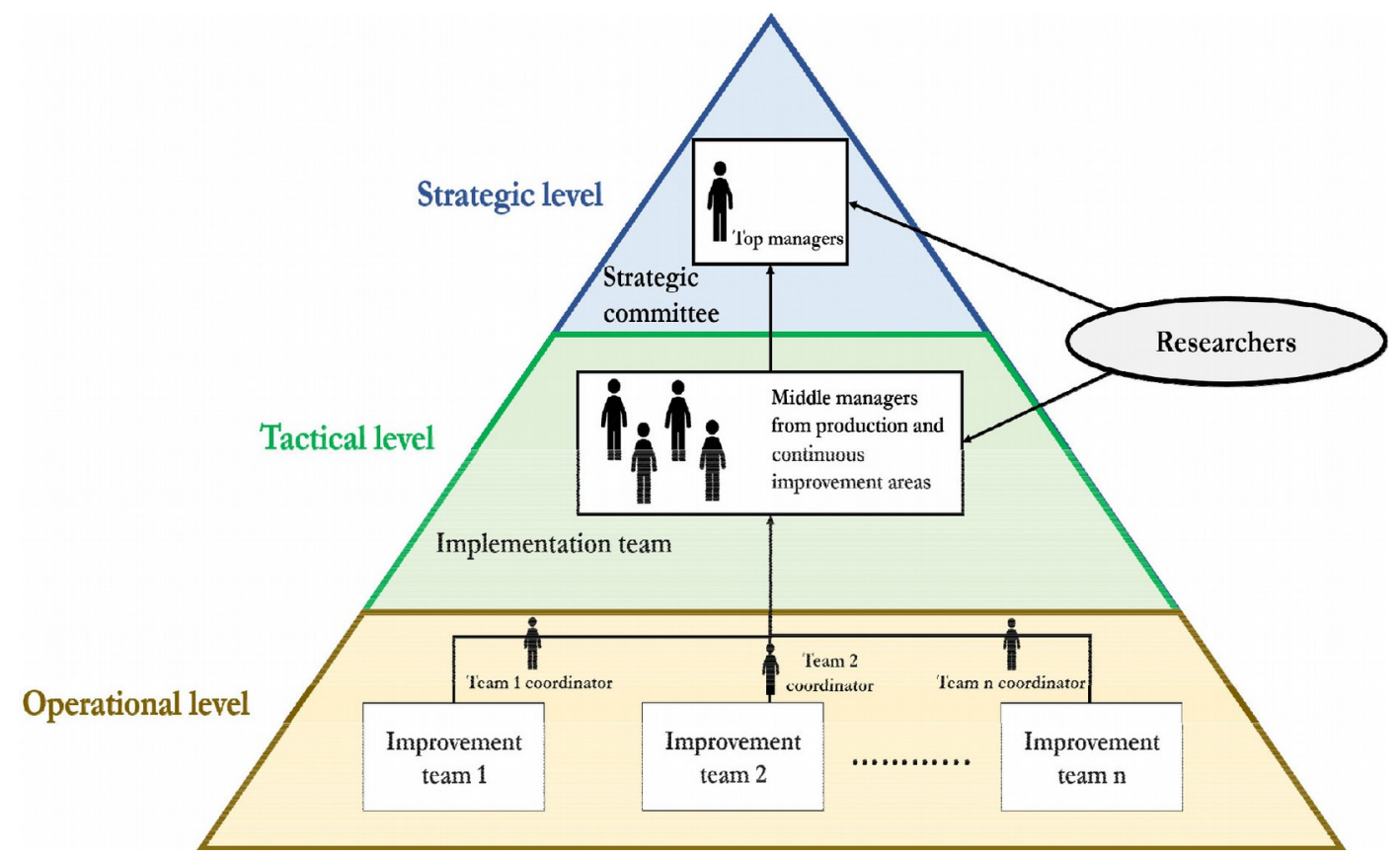

Figure 3. Proposed organizational structure

As Figure 3 shows, the organizational structures described (particularly the improvement team and the implementation team) are highly group-based in character. The reason for this decision lies in the many studies in which collective work appears as a way of strengthening empowerment and personnel implication. (García-Arca \& Prado-Prado, 2011; Jaca, Viles et al., 2012; Paipa-Galeano, Bernal-Torres, Otálora, Nezhad \& González-Blanco, 2020; Prado-Prado et al., 2020). Along the same lines, the name "team" was applied to the groups precisely to strengthen the feeling of belonging and collaboration among their members. This is fundamental bearing in mind that teamwork can help make the experience more intense and contribute to a more deep-rooted participative philosophy. This claim is supported by the study by Jaca, Viles et al. (2012), which identifies teamwork as one of the key factors for achieving sustainability in participation programs. This clearly links with the objectives set at the start of the study and is the reason why the authors have decided to set up structures of this type. 


\section{Design and Functioning of the Improvement Teams}

All participation-based continuous improvement projects have people as a fundamental pillar. This case is no exception. For that reason, this section focuses on the design and functioning of the improvement teams on the basis of scientific evidence. Figure 4 contains a summary of the most relevant factors that have been identified previously by other researchers.

The aspects considered here are sorted into two groups. One is made up of the factors of the functioning and design of the improvement team (therefore, internal factors), while the other includes all the aspects that have to be provided from outside the team (therefore, external factors). The following subsections describe these questions in more detail, with reference to how they have been structured in this project.

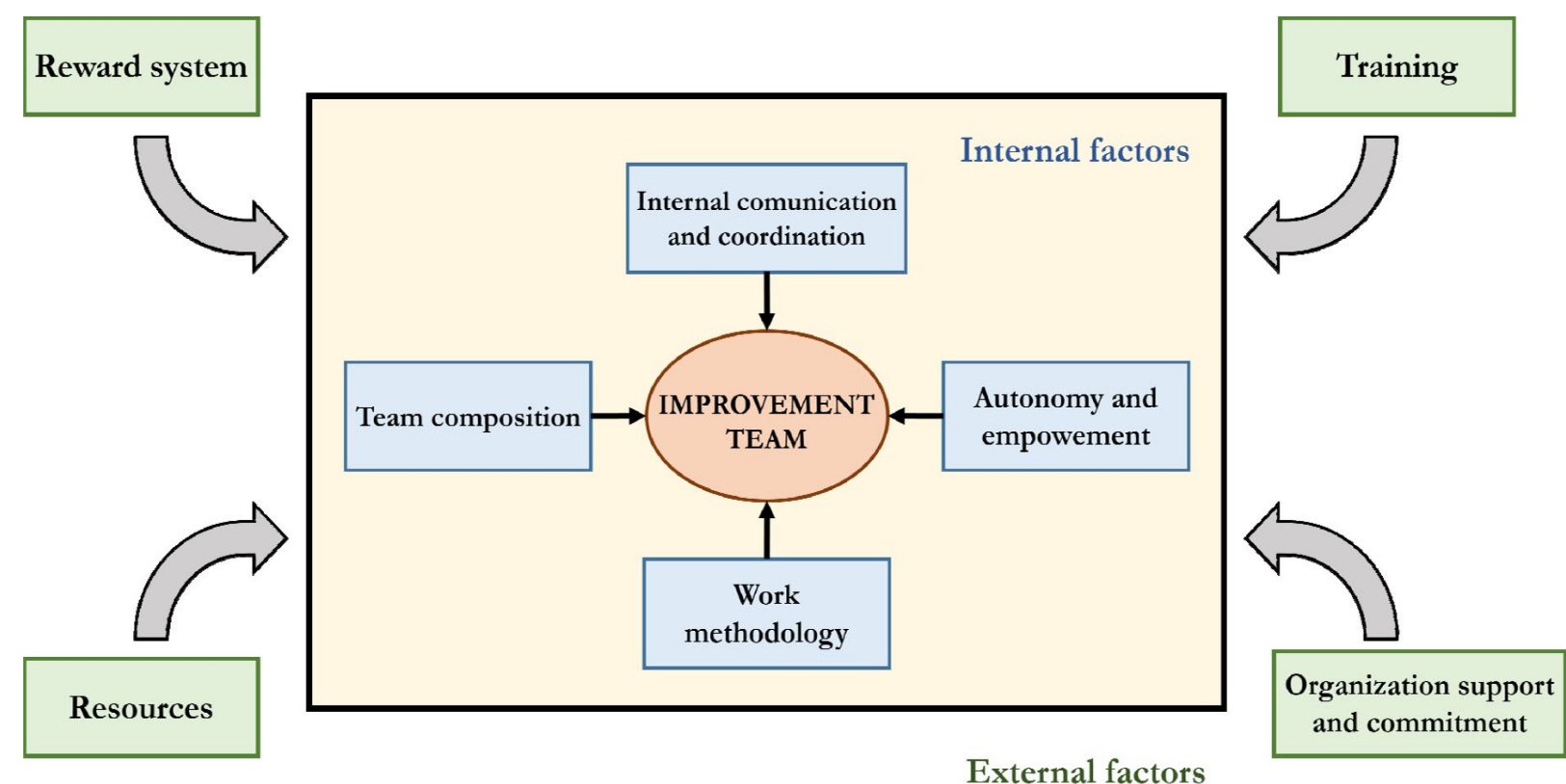

Figure 4. Critical factors in improvement teams design and operation

\subsection{Internal Factors}

The critical internal factors for success are the following:

\subsubsection{Team Composition}

One important aspect to determine is who will be members of the improvement team. In this regard, it is desirable to include workers from different posts and hierarchical levels (Marín-García et al., 2008) in order to obtain the most complete and global vision of the problems. However, this question should be addressed jointly with the voluntary nature of participation. This is because in some contexts participation tends to be considered as compulsory due to its connection with work (Brunet \& New, 2003), although there are many nuances that can be applied to that statement. People's motivation is the driving force for these systems (García-Arca et al., 2018; Jurburg, Viles, Tanco \& Mateo, 2017; Magnusson \& Vinciguerra, 2008) and designating a person for inclusion in a working team could hold it back or even destroy its proper functioning. This is particularly critical if it is the first experience (as in this case), because it can lead to major obstacles in future experiences. For this reason, the most advisable approach is to design a diverse team in terms of tasks and responsibilities made up of the most devoted personnel (Prado-Prado et al., 2020) and led by a coordinator with leadership skills.

\subsubsection{Work Methodology}

The work methodology is one of the pillars for success of improvement teams. The first stage of the process is the identification of deficiencies or opportunities for improvement. Once they have been identified, solutions are 
worked on without losing sight of how they evolve as a result of the implemented actions. In this regard, teamwork has been shown to be the facilitator par excellence (Jaca, Santos, Errasti \& Viles, 2012; Paipa-Galeano et al., 2020; Prado-Prado et al., 2020), as it strengthens the capacity to respond successfully to the identified problems. Once a suitable response is found, the focus must be put on standardizing the improvements made so that they can survive over time (García-Arca \& Prado-Prado, 2011).

All the work of these teams but be oriented towards achieving the organization's strategic goals (Jaca, Viles et al., 2012), in such a way that the personnel can also identify with it and see it as their own. Thus, an analytical approach must predominate and all decisions should be taken on the basis of objective data (Stratton \& Warburton, 2003). Under this approach, it is fundamental to implement Key Performance Indicators (KPIs) that enable continual assessment of the implemented improvements (García-Arca et al., 2018). This will make it possible to reorient the team's work if it is unsatisfactory.

\subsubsection{Autonomy and Empowerment}

The level of autonomy of the improvement team is another aspect that must be considered. In this sense, the team's capacity could be limited to one or several of the stages of the improvement process (e.g., deficiencies identification) or could be fully extended. Studies in this field state that equipping the team with autonomy at all stages of the process contributes in a positive way to the motivation of personnel (Jurburg et al., 2017), which in turn fosters sustainability in participation and in continuous improvement (Jaca, Viles et al., 2012). Furthermore, empowering the team encourages creativity among members and helps them to be more aware of existing difficulties and of the power that people have to be agents for change. That is why it is recommendable for employee participation to take place in the design, development and implementation of solutions (García-Arca \& Prado-Prado, 2011). Nevertheless, whichever approach is implemented, it is important to establish and make clear from the outset of the experience how much autonomy the team will have. Misunderstandings and ambiguities on this matter can give rise to complete demotivation among employees as they see their capacities to transform their environment limited.

\subsubsection{Internal Communication and Coordination}

To maintain a methodology based on teamwork, it is essential that the members of the improvement team communicate and coordinate appropriately with each other. Communication usually takes place by setting up a system of working meeting, and the way they occur is one of the points that generates most controversy. From the worker's point of view, the most reasonable thing would appear to be to hold meetings during work hours because the activity is linked to their work. However, from a production standpoint, holding meetings when operatives should be working means that they are not doing their usual job, which penalizes production. This problem should be solved by seeking agreement among all the parties so that meetings are held half in and half out of work hours. Furthermore, a timetable should be sought that allows all team members to attend, which might mean that a special timetable is used if workers are on different shifts.

Regarding how the meetings function, they should have a set time limit and be a place where the work undertaken is presented, ideas are debated and decisions are made (Prado-Prado, 2009). However, the work of team members must be concentrated fundamentally during the periods between meetings. The role of the team coordinator is vital in order to maintain that balance (Magnusson \& Vinciguerra, 2008).

\subsection{External Factors}

From an external point of view, the following issues are particularly relevant:

\subsubsection{Resources}

A fundamental aspect of the success of employee participation is that the firm (particularly its management) makes the resources needed available. This apparently obvious point is often one of the reasons for failure when such systems are set up (García-Arca et al., 2018; Paipa-Galeano et al., 2020). Although most deficiencies and improvement opportunities can be tackled without the need for investment, employee participation itself consumes human and material resources. The most relevant resource is usually people's time, such as when supervisors 
manage the participation program or employees from other departments carry out the activities suggested by the improvement team. A system without resources means slowness, which can lead to employee demotivation if no progress is seen (Marín-García et al., 2008). It is vital, therefore, that management is conscious of this issue and provides the resources needed for the system to function properly.

\subsubsection{Organization Support and Commitment}

As mentioned, the support and commitment of everyone in the organization is an indispensable condition for the success of any formula for participation. On the basis that there is initial support and commitment from the managers, it is crucial to obtain the same from all the other workers at the firm. In the case of improvement teams, particularly, the possibility of participating directly in the program is not given to all personnel. That is why it is important that team members take on the role of representatives for their coworkers (García-Arca \& Prado-Prado, 2011) and act as communication link for their ideas and initiatives. This will help the whole task force to see the improvement team as a useful instrument and, therefore, to support it. Something similar happened with the trade union (O'Donoghue et al., 2011), which should be brought on board to the cause if it is initially not in line with the initiative.

\subsubsection{Training}

Training is a hackneyed topic in the literature on employee participation. It seems clear that it is practically essential, particularly if team members belong to highly operational levels. Under the empowerment approach, training should cover analysis methodologies and improvement tools in order to give members the knowledge that will allow them to carry out all the stages in the improvement process (Prado-Parado, 2009; Jaca, Santos et al., 2012). However, it may be preferable not to overload participants with too many theoretical lessons. In this regard, learning by doing is often the most effective approach (García-Arca et al., 2018).

In addition to this issue, it seems clear that training has a positive effect on personnel motivation and the long-term sustainability of the continuous improvement (Jurburg et al., 2017). Moreover, training gives the project substance and importance. Training helps to demonstrate the commitment of the firm's management to the idea that welltrained, motivated people are its best competitive advantage.

\subsubsection{Reward System}

One of the most important aspects, yet one which often receives the least attention, is how employees could be rewarded for their participation. On the basis that forming part of an improvement team will initially be an effort that manifests itself as an improvement in competitiveness, it seems reasonable to make a gesture of gratitude to the team members. There are three alternatives for doing so: economic reward, reward in kind and recognition. In this sense, there is no clear consensus as to which is the most appropriate (Jaca, Viles et al., 2012)

Under an approach in which the improvement of processes forms part of the work, the reward (in this case economic) would be the salary itself (Brunet \& New, 2003). However, this approach has the setback that no distinction would be made between the people who participated actively and those who did not. A basic distinction would be to give some recognition to the team members, which could be combined with symbolic rewards in kind (e.g., days off). This would make it possible to show gratitude while at the same time strengthening the firm at a human level. However, this solution should be complemented (if there is a desire to take things further) with an economic reward depending on the object of improvement. Such an incentive can help to boost the motivation of participating personnel, although it is important to bear in mind that this reward has to coexist with company policies in other areas.

\section{Development of the Experience}

Bearing in mind the methodological aspects described above, the researchers set up the improvement project in the facilities of the Spanish food manufacturer. The experience began with the Pre-phase: Understanding context and global vision, which had the objective of obtaining a general understanding of the firm's production system. To do so, the researchers carried out a series of interviews with the high-level management in which they asked about aspects such as how the factories functioned at a production level, the organizational structure and relations 
between departments. After gaining a global vision, they exchanged views with the same managers in order to structure and agree on the project's approach.

Once the main processes and sections of the firm were known, a decision was taken to look more in depth at the state of the production system. This was the time when the implementation team was set up. It included the firm's managers in the areas of production and continuous improvement and the researchers. This group of specialists, made up of a total of six members, launched an exhaustive analysis process of the work parts that managed to determine the potential savings of the various production lines. To do so, two indicators were used, that made it possible to structure potential savings according to their nature: efficiency and performance. The former refers to the difference between the production obtained and what would be obtained if the line work continuously at full speed. The performance indicator, on the other hand, quantified decreases or losses of raw material that were produced throughout the whole production process. Finally, on the basis of the potential savings obtained, the management set a target of $10 \%$ of the potential saving for each production line.

As a final reflection in this stage, the implementation team ranked the lines in terms of their priority for action. Line 1 of factory 1 was highlighted as a first priority as it produced the greatest volume and added value for the firm. Consequently, the first improvement team was launched on that line and served as a pilot experience before a systematic roll out to the other lines.

\subsection{Launch and Pilot Experience}

The improvement team for line 1 of factory 1 was mainly made up of operational staff. A pre-defined structure was designed so that all profiles were represented. That structure included the factory manager (team coordinator), the supervisors, a maintenance operative, a logistics operative and a group of production line workers (representing all three shifts). Using this structure, a total of 10 workers who matched the required profiles were sought to voluntarily join the team. The task of coordinating the team members fell to the researchers. Before this first improvement team began its activity, the members were invited to a training session on continuous improvement an improvement tools in order to give them the knowledge they would need. After training, the improvement team began with a brainstorming session, at which each participant put forward ideas that, from their standpoint, would help to improve the production line's performance. A total of 170 ideas were obtained.

After this first stage (which would correspond to Phase 1: Data gathering), a cyclical process is launched in which proposals are analyzed and evaluated, actions are planned (Phase 2: data analysis and action planning), executed and their suitability evaluated (Phase 3: Action implementation and evaluation) and data gathering is resumed. This cycle, run for each proposal, was executed by the members of the improvement team in such a way that each idea was assigned to the person who contributed it. In that way, an empowerment approach was applied to the operatives who proposed, studied and implemented their own ideas. The work described was carried out over a two-month period, during which time a total of five working meetings were held (each lasting an hour at most and with 15 days between them). The meetings were intensive and were only devoted to sharing the results that had been obtained and taking decisions as to whether particular proposals should be implemented. Throughout the two months, both the implementation team and the strategic committee provided support and monitoring tasks for the improvement team's activity (Meta-phase: Monitoring).

Once their activity was finished, the members of the improvement team held a public event to present the results obtained to the managers. During this act, the managers praised the team's work and as a show of gratitude gave each participant a small gift as a memento. Furthermore, given that the savings obtained exceeded the 10\% potential savings, they were also given a small economic reward. Finally, the improvement team was disbanded. However, the end of this stage did not mean the end of improvement work on the line because actions of greater scope, which required more time for analysis and implementation, would still being studied and carried out by the implementation team until they were finished.

\subsection{Extension of the Project}

Immediately after the first improvement team had been disbanded, a new improvement team was launched on line 2 at the same factory. The time between these two events was kept to a minimum so as not to lose the latent 
transforming potential at the plant and to keep alive the excitement from the first successful experience. However, there were notable differences with the launch of this team compared to the first because it was created and coordinated internally by the production area and continuous improvement managers without tutoring from the researchers, who only supervised this time. At the same time, the researchers shifted their activity to line 1 at factory 2 in order to rapidly extend the methodology and culture of continuous improvement throughout the company. Just as for the first factory, an improvement team was created for line 1 at factory 2 . The methodology followed in this case was identical to that used to set up all the others. After this improvement team was disbanded, another, led by managers from the firm, was launched on line 2 at the same factory. The researchers then moved to factory 3 with the same approach and finished their work by setting up an improvement team for line 1 at that factory.

Once the work of the different improvement teams was concluded, the researchers prepared and distributed a survey. Its aim was to assess the impressions and perceptions of the workers regarding the methodology used and to see how deeply rooted the participative culture had become. The survey, which combined open questions with a number scale (1-5) with dichotomous questions, was filled out by workers who had participated in the different improvement teams. Regarding the structure of the survey, participants were first asked to evaluate their experience in a general way. This was followed by a first block of questions on their participation in similar future experiences. This set of questions aimed to assess how deep-rooted the participative culture was and identify the causes of interest or disaffection in participating in further experiences. The second block of questions was devoted to studying the methodology followed during the experience. Thus, an assessment was requested on fundamental aspects of the methodology that could be easily evaluated by the workers. Finally, a third block of questions covered the participants' personal experience, highlighting those aspects that they considered most interesting and those that they would have preferred to see managed in another way. The final section asked participants to evaluate a series of aspects related to how belonging to an improvement team had affected them. The survey is included here as Appendix A.

\section{Results}

The improvement project has obtained clearly tangible results. On the one hand, production improvements have been achieved which have brought about major savings annually. On the other hand, development of an improvement program by means of participation mechanisms has made it possible to strengthen a feeling of belonging among workers and allow the philosophy of continuous improvement to take root within the organization. Both blocks of results are described below.

\subsection{Economic Results}

Analysis of the economic results centers on the three production lines for which the researchers have been an active part of the improvement process. Thus, this section highlights the importance of the production improvements reached during this experience and the contribution, in the number of ideas, from the participants.

Line 1 at factory 1 obtained very positive economic results, which was coherent with the great potential for improvement the installation had shown. Thus, the total saving was around $40 \%$ of the line's potential saving, far exceeding the $10 \%$ target set when the study started. According to the established indicators, this saving can be broken down into the items of efficiency and performance. In this regard, a little under $10 \%$ of the savings were achieved by improving the line's efficiency, while $90 \%$ were obtained by improving performance with raw materials. This was due to the fact that the improvements carried out were mainly related to monitoring and detecting extraneous elements in the product separation process and with greater control of product sampling. The low percentage of improvement in efficiency, however, was due to the need to make major investments in order to achieve higher speeds on some sections of the line, which offered little profitability. Furthermore, the improvements made were not all located in the production sphere but also included other aspects that are vital for workers such as safety or ergonomics.

The savings achieved on line 1 at factory 2 were substantially lower. To be specific, savings of just over $2 \%$ of the line's potential were obtained, $20 \%$ of which refer to efficiency and $80 \%$ to performance. Such low results can mainly be put down to the high level of automation on the line, where major investments with a long return period 
were needed to improve performance. At the same time, this line was devoted to manufacturing a type of product with a low economic value, which meant that the few improvements that could be made in performance did not have a great effect on savings. In short, most of the savings came from small actions with little individual repercussion, although all together saved a considerable amount of resources.

Finally, on line 1 at factory 3 , the economic results were once again quite positive. The saving made on this line exceeded $22 \%$ of the potential saving, which was well over the target $10 \%$ set by the firm. Like line 1 at factory 2 , the ratio here for savings made in performance or efficiency was also 80:20.

These good overall results can be explained, first, by the existence of many highly manual job posts and a working method that was little optimized and, second, by the large number of ideas put forward by the workers. In this regard, the three improvement teams provided 170,156 and 192 ideas each, which is a good demonstration of the commitment workers had to the project and the wide-ranging possibilities for improvement the lines had. Logically, not all the ideas could be addressed by their respective improvement team, which was due to the subject of competences or simply the time available. For that reason, the implementation team has played a fundamental role throughout the project, keeping study of long-term development ideas and studying others autonomously once the improvement team had finished. All the work amounted to approximately $€ 150,000$ of savings annually, which is a notable improvement in the firm's production system.

\begin{tabular}{|r|r|r|r|r|}
\hline & $\begin{array}{c}\% \text { of total } \\
\text { saving }\end{array}$ & $\begin{array}{c}\% \text { savings in efficiency } \\
\text { over the total }\end{array}$ & $\begin{array}{c}\text { \% savings in performance } \\
\text { over the total }\end{array}$ & $\begin{array}{c}\text { Total ideas } \\
\text { proposed }\end{array}$ \\
\hline Line 1 - Factory 1 & $41.56 \%$ & $9.36 \%$ & $90.64 \%$ & 170 \\
\hline Line 1 - Factory 2 & $2.56 \%$ & $21.05 \%$ & $78.95 \%$ & 156 \\
\hline Line 1 - Factory 3 & $22.37 \%$ & $21.95 \%$ & $78.05 \%$ & 192 \\
\hline
\end{tabular}

Table 1. Summary of the economic results

\subsection{Cultural and Organizational Results}

This participation experience was well received by the workers at the firm, according to the results of the survey filled in by participants after the intervention. In this regard, it is worth noting that $100 \%$ of respondents indicated that the use of this formula for participation seemed interesting and positive. In fact, most considered that the experience had served to foster teamwork and encourage the involvement of personnel from all departments.

In the block of questions about participation in future experiences, the results were quite striking. It was seen that only $78 \%$ of the participants would like to participate in an improvement team again. That means that almost a quarter of them would not repeat, which is undoubtedly bad news from an organizational point of view. However, when the results were broken down, it could be seen that the majority of those opinions (around $70 \%$ ) came from the responses of members of the improvement team on line 1 at factory 2, where the economic results were not altogether satisfactory. Thus, only $60 \%$ of the workers on that line would be willing to participate in another experience. The reason put forward by the respondents is simple: a great deal of effort for very few results. This generalized opinion denotes some disaffection among workers at not having been able to reach the improvement objective set (with its associated economic reward). This is in contrast to the opinion of the workers on the other two lines, where $83 \%$ and $100 \%$ of respondents showed an interest in repeating the experience. In fact, the reason put forward by the workers showing no interest in repeating the experience was that they favored the idea of letting their colleagues participate so that everyone could have the chance to take part in a similar experience.

The third block of questions asked participants about the best and worst methodological aspects, requiring an assessment based on a scale of 1-5. Thus, the most highly valued aspect was the use of brainstorming technique, which received an average score of 4.6. This high score confirms the efficiency of this technique and strengthens its role as a way of allowing all participants to express their ideas and be an active part of the improvement process. At the other extreme, intersessional work only received an average score of 3.5. Even though this point received a 
relatively high score, the respondents seemed to think that more time was needed (longer than 15 days) to implement the improvement actions. Regarding this issue, and in line with what has been mentioned earlier, when the results for the improvement team for line 1 at factory 2 are analyzed separately, they are again striking. The members of that team highlighted as the methodology's most negative aspect (with an average score of 3 ) the problem selection process. This circumstance reinforces, once again, the hypothesis that the perception of some participants has been influenced by the economic dimension.

In the methodology block, respondents were also asked to use a 1-5 scale to evaluate the following aspects linked to the continuous improvement program: implementation team dedication, coordinator's work, improvement team empowerment, available resources and training. The evaluation of all aspects was quite positive since all of them received a score higher than 4 out of 5 . However, the most notable aspect was implementation team dedication (average score of 4.3). This underlines the fundamental role of the implementation team in experiences like this as it is responsible for leading the improvement process and ensuring that the proposed actions are implemented.

In the block covering the participants' personal experience, one open question asked respondents to indicate the most interesting aspect of their participation. Approximately $70 \%$ concurred that sharing ideas with their coworkers and discovering other points of view made up the most outstanding aspect. Likewise, they were also asked which matters they would have preferred to see managed in a different way. This question saw the widest disparity of answers, although most highlighted the same point: the lack of time for studying and implementing improvements. This opinion shows that the participants were not satisfied with the volume of ideas studied and would have liked to have addressed even more.
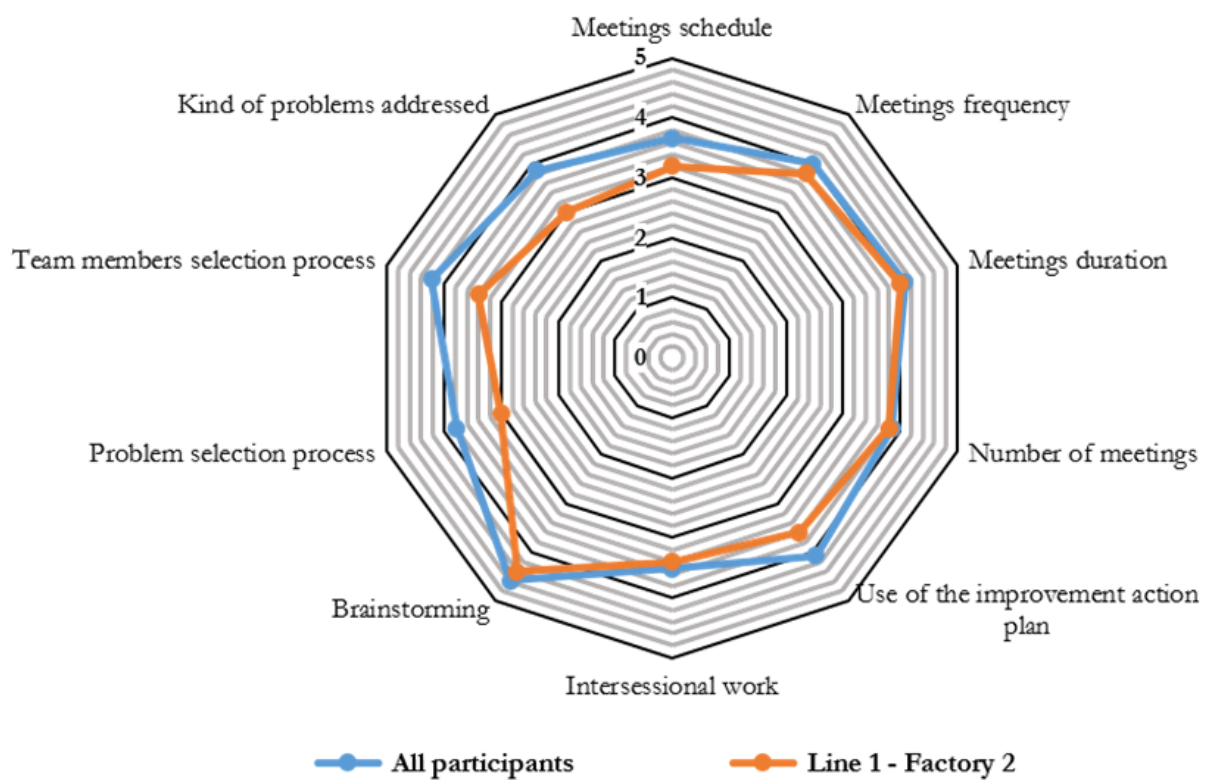

Figure 5. Methodological aspects assessment (All participants vs Line 1 - Factory 2)

\begin{tabular}{|l|r|r|r|r|}
\hline & Line 1 - Factory 1 & Line 1 - Factory 2 & Line 1 - Factory 3 & \multicolumn{1}{|c|}{ Total } \\
\hline Number of ideas proposed & 170 & 156 & 192 & 518 \\
\hline Number of ideas addressed & 107 & 68 & 96 & 271 \\
\hline \% ideas addressed & $62.9 \%$ & $43.6 \%$ & $52.6 \%$ & $52.3 \%$ \\
\hline
\end{tabular}

Table 2. Percentage of ideas addressed with respect to the total proposed

In addition to the above aspects, the block of questions on personal experience asked participants to evaluate the following aspects on a scale of 1-5: work environment, improvement of professional development, recognition of worth and personal satisfaction (Figure 6). In this evaluation, it is worth noting the high score obtained by work 
environment (average score of 4.6). For other aspects such as personal satisfaction or improvement of professional development, although the global assessment has been positive, there was a disparity of opinions among the members of the improvement teams. Furthermore, as with the other blocks of questions, the scores for these aspects from the improvement team on line 1 at factory 2 were appreciably lower. Finally, the surprisingly low score for an aspect as important as recognition of worth is notable. This is probably due to the low percentage of ideas implemented compared to those proposed in some specific cases, as the low average evaluation of this aspect responds to the very low scores given by some of the participants.

In short, except for specific exceptions, the evaluation of workers taking part in the project has been very positive. This underscores the dual character of participation, which is able to increase the feeling of belonging to the organization and job satisfaction, both highly relevant aspects in the self-fulfillment of any person. Furthermore, the success of the experience contributes, without doubt, to the sustainability of the improvement culture in the company, putting the organization on the path towards operational excellence.

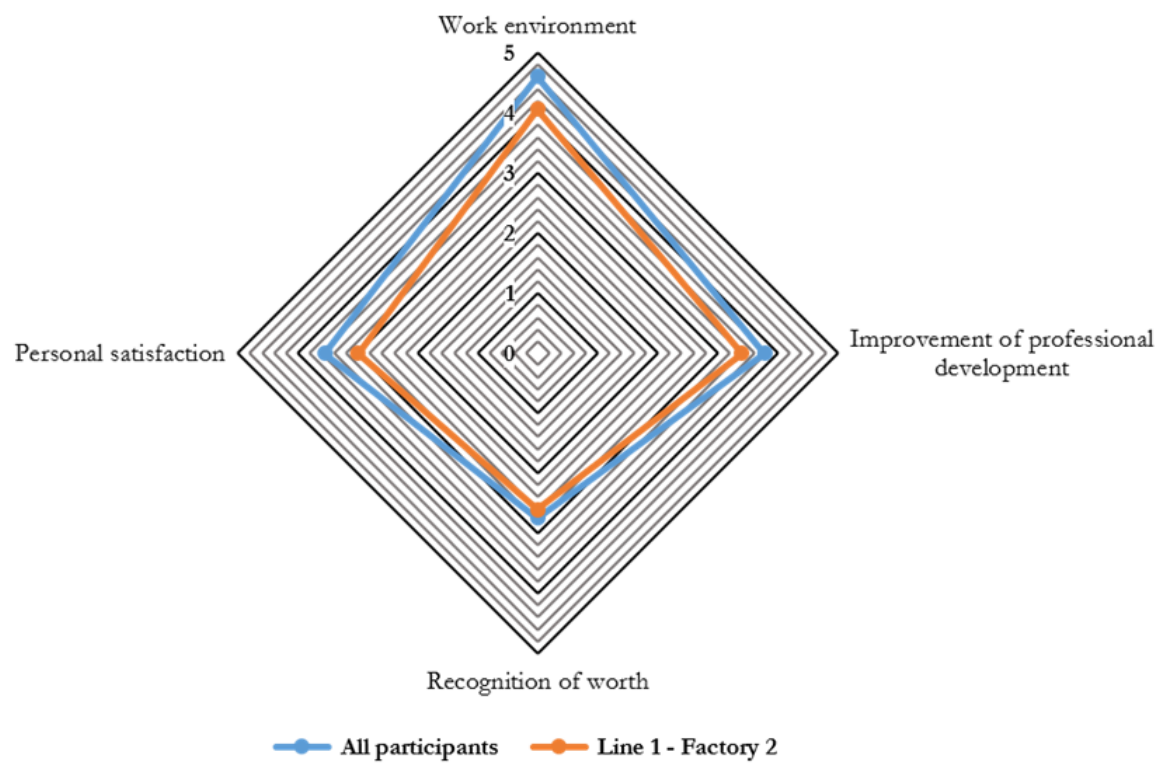

Figure 6. Participants experience assessment (All participants vs Line 1 - Factory 2)

\section{Discussion and Lessons Learned}

The results obtained in this study allow considerations to be made at both a human and an economic level. Regarding the economic sphere, the results obtained are clearly positive. Obviously, obtaining $€ 150,000$ of annual savings is very good news for the organization, as it permits an increase in its competitiveness. However, the "surprising" part of this news is that it has been achieved by means of a project that cost the organization practically nothing, as no large expenditures were needed. It was simply that a potential saving existed in the production system and the organization has studied the way to obtain it. This approach forms the basis of continuous improvement and, particularly, employee participation (Brunet \& New, 2003).

Regarding the cultural and organizational sphere, the results of the study can also be considered to be very positive. The general satisfaction of workers with the philosophy of participative improvement is a fundamental aspect that can be drawn from the results of the study. In part, this could be due to the empowerment approach adopted, in which the worker plays the main role throughout the process of identifying, studying and implementing the improvement. In this way, the worker tends to increase their feeling of belonging to the organization, which has a positive repercussion on their motivation and commitment (Brunet \& New, 2003; Stimec \& Grima, 2019). All these attributes help the improvement philosophy to become more deep-rooted through participation, as it values the role of people and makes it possible for this type of practice to be maintained in future. 
However, despite the positive results at a cultural and organizational level, it is important and necessary to consider the dissatisfaction of the members of the improvement team for line 1 at factory 2 . There is some consensus in the academic literature that establishing improvement objectives is positive for the performance of a participation program (García-Arca et al., 2018; Jaca, Viles et al., 2012). Nevertheless, the objectives must be attainable if worker motivation is to be achieved. Therefore, given the technical difficulties observed on this line, it could be that establishing the same objective for all the improvement teams was not a good decision. Furthermore, it is not known whether the root cause of the dissatisfaction could have been that, unlike the other improvement teams, no economic reward was received. This effect, and even the suitability of economic rewards for participation, is an issue that future research must study in more depth.

Within the issues addressed in this case, the relationship existing between the economic sphere and the human sphere must not be forgotten. Historically, the economic perspective has been dealt with as an area linked purely to management or strategy and removed from operational levels. This could not be further from the truth according to the results obtained in this study. Thus, it is the commitment of the organization's workers that, channeled through a structured employee participation system, makes it possible to obtain improvements at an economic level. In this sense, some authors (Birdi, Clegg, Patterson, Robinson, Stride, Wall et al., 2008; Chang \& Chen, 2011) have already demonstrated that implementing management approaches such as continuous improvement depends on the simultaneous implementation of practices with greater worker involvement. That is why it is fundamental to pay attention to the most operational levels, as that is where the most unnoticed opportunities for improvement are usually to be found. (Boer et al., 2017, Brunet \& New, 2003; Marksberry et al., 2014).

Despite the above, any effort aimed at improving competitiveness will be useless if participation is not appropriately structured. There are other cases in the literature, such as García-Arca and Prado-Prado (2011), Jaca, Santos et al. (2012), O’Donoghue et al. (2011) or Rapp and Eklund (2002), in which participation has been structured in a different way from this study, but always with mechanisms to guarantee proper functioning enabled. However, and to a lesser extent, there are also experiences in which participation has not worked as expected precisely for that reason. One such case, by Ramesh and Ravi (2017), describes an Indian firm where the participation program did not work, among other reasons, because of the weakness of the organizational structures designed, the lack of an empowerment approach and an inadequate rewards system. This example leads to the conclusion that a large part of the success of the project lies in the adequate and detailed structuring of the participation system.

Finally, even though employee participation is a powerful tool for improvement, it should not be understood as a "magic formula" that can be applied to all types of situations. An example of this is line 1 at factory 2. Nevertheless, this does not mean that the line does not have potential for improvement, but rather that in order to make the most of it, a large economic investment would have been needed. This is a different approach, although complementary, to the one that underlies the philosophy of continuous improvement, as it is the result of saving the economic investment (Brunet \& New, 2003). Therefore, there is a need to be aware that continuous improvement (and participation) has its limits and, thus, not all problems or opportunities can be tackled by using it.

\section{Conclusions}

In this action research study, the performance of the production system at a Spanish food manufacturer has been improved through employee participation. In line with the proposed objectives, the experience has obtained positive results not only at an economic level but also at a cultural and organizational level. This has been possible thanks to the creation of improvement teams on each of the firm's production lines and to an organizational structure that involves all levels of the organization. In this way, a considerable economic sum has been saved in the firm, which has helped increase its long-term competitiveness. Likewise, after the work of the improvement teams was finished, the participants filled out a survey in order to find out how deep-rooted the participative culture had become. Participants were in general satisfied with the experience. However, some nuances in the level of satisfaction were found depending on the improvement team. As a result of the disparity, a relationship was 
observed between a low level of satisfaction and a low level of savings, which signals a new path for future research on the topic.

This study has implications from both a practical and theoretical point of view. Regarding theory, this is one of the first studies which evaluates how deep-rooted participation is after an improvement experience. On the basis of that, numerous questions have arisen for future research. For example, how employees are recognized and rewarded for their participation and what effect these practices have on involvement and motivation are relevant aspects that have not been explained by this study. In the same way, the influence of the social, cultural and organizational context when it comes to applying improvement philosophies is another question that future work must deal with. Regarding practical implications, this study describes and uses a methodology for carrying out an improvement project based on employee participation in a structured way. Implementing projects of this type will help organizations to be able to improve their competitiveness while conferring on people the important role that they deserve.

\section{Declaration of Conflicting Interests}

The authors declared no potential conflicts of interest with respect to the research, authorship, and/or publication of this article.

\section{Funding}

The authors received no financial support for the research, authorship, and/or publication of this article.

\section{References}

Bessant, J., \& Francis, D. (1999). Developing strategic continuous improvement capability. International Journal of Operations \& Production Management, 19(11), 1106-1119. https://doi.org/10.1108/01443579910291032

Birdi, K., Clegg, C., Patterson, M., Robinson, A., Stride, C.B., Wall, T.D. et al. (2008). The impact of human resource and operational management practices on company productivity: a longitudinal study. Personnel Psychology, 61(3), 467-501. https://doi.org/10.1111/j.1744-6570.2008.00136.x

Boer, H., Berger, A., Chapman, R., \& Gertsen, F. (2017). CI changes from suggestion box to organisational learning: continuous improvement in Europe and Australia. New York: Routledge.

Brunet, A.P., \& New, S. (2003). Kaizen in Japan: an empirical study. International Journal of Operations \& Production Management, 23(12), 1426-1446. https://doi.org/10.1108/01443570310506704

Chang, P.C., \& Chen, S.J. (2011). Crossing the level of employee's performance: HPWS, affective commitment, human capital, and employee job performance in professional service organizations, International Journal of Human Resource Management, 22(4), 883-901. https://doi.org/10.1080/09585192.2011.555130

Christopher, M. (2000). The agile supply chain: competing in volatile markets. Industrial marketing management, 29(1), 37-44. https://doi.org/10.1016/S0019-8501(99)00110-8

Coughlan, P., \& Coghlan, D. (2002). Action research for operations management. International Journal of Operations \& Production Management, 22(2), 220-240. https://doi.org/10.1108/01443570210417515

Fadaki, M., Rahman, S., \& Chan, C. (2019). Leagile supply chain: design drivers and business performance implications. International Journal of Production Research, 1-23. https://doi.org/10.1080/00207543.2019.1693660

Fagundes, L.D., Amorim, E.S., \& da Silva Lima, R. (2017). Action research in reverse logistics for end-of-life tire recycling. Systemic Practice and Action Research, 30(5), 553-568. https://doi.org/10.1007/s11213-016-9408-1

Fernández Vázquez-Noguerol, M., Rodríguez-García, M., \& Prado-Prado, J.C. (2018). Aplicación de técnicas Lean Construction a través de un método de Action Research en los procesos de gestión de una empresa constructora. Dirección y Organización, 65(1), 90-103.

Fredriksson, M., \& Isaksson, R. (2018). Making sense of quality philosophies. Total Quality Management \& Business Excellence, 29(11-12), 1452-1465. https://doi.org/10.1080/14783363.2016.1266245 
Fullerton, R.R., Kennedy, F.A., \& Widener, S.K. (2014). Lean manufacturing and firm performance: the incremental contribution of lean management accounting practices. Journal of Operations Management, 32(7-8), 414-428.

https://doi.org/10.1016/j.jom.2014.09.002

García-Arca, J., \& Prado-Prado, J.C. (2011). Systematic personnel participation for logistics improvement: a case study. Human Factors and Ergonomics in Manufacturing \& Service Industries, 21(2), 209-223.

https://doi.org/10.1002/hfm.20246

García-Arca, J., Prado-Prado, J.C., \& Fernández-González, A.J. (2018). Promoting structured participation for competitiveness in services companies. Journal of Industrial Engineering and Management, 11(2), 196-206. https://doi.org/10.3926/jiem.2514

Jaca, C., Santos, J., Errasti, A., \& Viles, E. (2012). Lean thinking with improvement teams in retail distribution: a case study. Total Quality Management \& Business Excellence, 23(3-4), 449-465.

https://doi.org/10.1080/14783363.2011.593907

Jaca, C., Viles, E., Mateo, R., \& Santos, J. (2012). Components of sustainable improvement systems: theory and practice. The TQM Journal, 24(2), 142-154. https://doi.org/10.1108/17542731211215080

Jørgensen, F., Boer, H., \& Gertsen, F. (2003). Jump-starting continuous improvement through self-assessment. International Journal of Operations \& Production Management, 23(10), 1260-1278.

https://doi.org/10.1108/01443570310496661

Jurburg, D., Viles, E., Tanco, M., \& Mateo, R. (2017). What motivates employees to participate in continuous improvement activities? Total Quality Management \& Business Excellence, 28(13-14), 1469-1488. https://doi.org/10.1080/14783363.2016.1150170

Lam, M., O'Donnell, M., \& Robertson, D. (2015). Achieving employee commitment for continuous improvement initiatives. International Journal of Operations \& Production Management, 35(2), 201-215.

https://doi.org/10.1108/IJOPM-03-2013-0134

Leach, D.J., Stride, C.B., \& Wood, S.J. (2006). The effectiveness of idea capture schemes. International Journal of Innovation Management, 10(3), 325-350. https://doi.org/10.1142/S1363919606001521

Magnusson, M.G., \& Vinciguerra, E. (2008). Key factors in small group improvement work: an empirical study at SKF. International Journal of Technology Management, 44(3-4), 324-337. https://doi.org/10.1504/IJTM.2008.021042

Marin-Garcia, J.A., \& Bonavia, T. (2015). Relationship between employee involvement and lean manufacturing and its effect on performance in a rigid continuous process industry. International Journal of Production Research, 53(11), 3260-3275. https://doi.org/10.1080/00207543.2014.975852

Marín-García, J.A., Pardo del Val, M., \& Bonavía Martín, T. (2008). Longitudinal study of the results of continuous improvement in an industrial company. Team Performance Management: An International Journal, 14(1/2), 56-69. https://doi.org/10.1108/13527590810860203

Marksberry, P., Church, J., \& Schmidt, M. (2014). The employee suggestion system: a new approach using latent semantic analysis. Human Factors and Ergonomics in Manufacturing \& Service Industries, 24(1), 29-39. https://doi.org/10.1002/hfm.20351

Näslund, D., Kale, R., \& Paulraj, A. (2010). Action research in supply chain management - a framework for relevant and rigorous research. Journal of Business Logistics, 31(2), 331-355. https://doi.org/10.1002/j.2158-1592.2010.tb00155.x

O'Donoghue, P., Stanton, P., \& Bartram, T. (2011). Employee participation in the healthcare industry: The experience of three case studies. Asia Pacific Journal of Human Resources, 49(2), 193-212.

https://doi.org/10.1177/1038411111400262

Paipa-Galeano, L., Bernal-Torres, C.A., Otálora, L.M.A., Nezhad, Y.J., \& González-Blanco, H.A. (2020). Key lessons to maintain continuous improvement: A case study of four companies. Journal of Industrial Engineering and Management, 13(1), 195-211. https://doi.org/10.3926/jiem.2973 
Prado-Prado, J.C. (2009). Continuous improvement in the supply chain. Total Quality Management, 20(3), 301-309. https://doi.org/10.1080/14783360902719519

Prado-Prado, J.C., García-Arca, J., \& Fernández-González, A.J. (2020). People as the key factor in competitiveness: a framework for success in supply chain management. Total Quality Management \& Business Excellence, 31(3-4), 297-311. https://doi.org/10.1080/14783363.2018.1427499

Ramesh, N., \& Ravi, A. (2017). Determinants of total employee involvement: a case study of a cutting tool company. International Journal of Business Excellence, 11(2), 221-240. https://doi.org/10.1504/IJBEX.2017.081433

Rapp, C., \& Eklund, J. (2002). Sustainable development of improvement activities--the long-term operation of a suggestion scheme in a Swedish company. Total Quality Management, 13(7), 945-969. https://doi.org/10.1080/0954412022000017049

Reason, P., \& Bradbury, H. (Eds.). (2001). Handbook of action research: participative inquiry and practice. London: Sage Publications.

Roemeling, O., Land, M., \& Ahaus, K. (2017). Does lean cure variability in health care? International Journal of Operations \& Production Management, 37(9), 1229-1245. https://doi.org/10.1108/IJOPM-07-2015-0452

Singh, J., \& Singh, H. (2015). Continuous improvement philosophy-literature review and directions. Benchmarking: An International Journal, 22(1), 75-119. https://doi.org/10.1108/BIJ-06-2012-0038

Stevens, G.C. (1989). Integrating the supply chain. International Journal of Physical Distribution \& Materials Management, 19(8), 3-8. https://doi.org/10.1108/EUM0000000000329

Stimec, A., \& Grima, F. (2019). The impact of implementing continuous improvement upon stress within a Lean production framework. International Journal of Production Research, 57(5), 1590-1605. https://doi.org/10.1080/00207543.2018.1494391

Stratton, R., \& Warburton, R.D. (2003). The strategic integration of agile and lean supply. International Journal of Production Economics, 85(2), 183-198. https://doi.org/10.1016/S0925-5273(03)00109-9

Tortorella, G.L., Marodin, G.A., Miorando, R., \& Seidel, A. (2015). The impact of contextual variables on learning organization in firms that are implementing lean: a study in Southern Brazil. The International Journal of Advanced Manufacturing Technology, 78(9-12), 1879-1892. https://doi.org/10.1007/s00170-015-6791-1

van Aken, J., Chandrasekaran, A., \& Halman, J. (2016). Conducting and publishing design science research: Inaugural essay of the design science department of the Journal of Operations Management. Journal of Operations Management, 47-48(1), 1-8. https://doi.org/10.1016/j.jom.2016.06.004 


\section{Appendix A. Assessment Survey of the Improvement Teams}

1. Do you find interesting and positive the existence of this participation system?

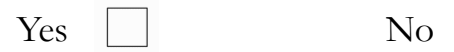

1.1 Why?

2. Would you like to participate in any other improvement team?

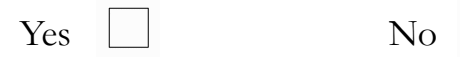

2.1. For what reasons?

3. Assess the following work methodology aspects (scale 1-5; 1, Unsuitable; 5, Very suitable):

\begin{tabular}{|l|l|l|}
\hline & Assessment (1-5) & Alternative in case of unsuitable \\
\hline Meetings schedule & & \\
\hline Meetings frequency & & \\
\hline Meetings duration & & \\
\hline Number of meetings & & \\
\hline Use of the improvement action plan & & \\
\hline Intersessional work & & \\
\hline Brainstorming & & \\
\hline Problem selection process & & \\
\hline Team members selection process & & \\
\hline Kind of problems addressed & & \\
\hline
\end{tabular}

4. Evaluate the following aspects of the continuous improvement program established in your company (scale 1-5; 1, Unsuitable; 5, Very suitable):

\begin{tabular}{|l|l|l|}
\hline & Assessment (1-5) & Alternative in case of unsuitable \\
\hline Implementation team dedication & & \\
\hline Work of the improvement team coordinator & & \\
\hline Information received on the operation of the improvement teams & & \\
\hline Facilities and equipment available to the improvement team & & \\
\hline Decision-making capacity within the Improvement Team & & \\
\hline
\end{tabular}

5. What did you find most interesting about your participation in the Improvement Team? 
6. What was the worst thing about your participation in the Improvement Team?

7. Evaluate how your membership in the Improvement Team has contributed in the following aspects (scale 1-5; 1 not at all important; 5 very important):

\begin{tabular}{|l|l|}
\hline & \multicolumn{1}{|c|}{ Assessment (1-5) } \\
\hline Work environment & \\
\hline Improvement of professional development & \\
\hline Recognition of worth & \\
\hline Personal satisfaction & \\
\hline
\end{tabular}

8. Make the observations that you think appropriate for the operation of the improvement teams.

Journal of Industrial Engineering and Management, 2021 (www.jiem.org)

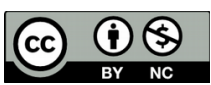

Article's contents are provided on an Attribution-Non Commercial 4.0 Creative commons International License. Readers are allowed to copy, distribute and communicate article's contents, provided the author's and Journal of Industrial Engineering and Management's names are included. It must not be used for commercial purposes. To see the complete license contents, please visit https://creativecommons.org/licenses/by-nc/4.0/. 